\title{
NOTAS
}

\section{CAMARONES DEL HENARES: ECOS Y DESLINDES EN JUAN RUIZ}

ÁNGEL GÓMEZ MORENO

Universidad Complutense de Madrid

En recuerdo de María Auxiliadora Cobos

La fórmula literaria del Arcipreste de Hita es tan eficaz que logra atrapar a un público diverso donde los haya: desde el lector bisoño que se da a su lectura escasamente pertrechado hasta el especialista que debe enfrentarse a no pocos obstáculos de naturaleza ecdótica o exegética y que, a pesar de disponer de todo tipo de herramientas, siente que, a cada paso, el Libro excede sus fuerzas. Que sea como digo realza la valía de la obra, que no se cae de las manos a pesar de la concentración de hapax legómena, de voces y frases foráneas de enorme complejidad, de sentencias con sentido equívoco y de referencias que, hasta la fecha, se tienen por impenetrables. Si a ello añadimos las dificultades derivadas de distinguir autor, narrador y personaje, de dar con un principio vertebrador para unos materiales tan diversos o de determinar la intención que movió a Juan Ruiz a escribir su Libro, sorprende que sus forofos se cuenten por decenas de miles. Aunque a todos se resista y a nadie desvele enteramente sus secretos, la obra irradia una energía que primero atrae y, en algún punto de la lectura, hace del lector curioso un prosélito más. Esto viene ocurriendo, sin interrupciones, desde el siglo XIV para acá; por ello, el suyo es un caso único en nuestra historia literaria.

Tantos escollos tiene que rara es la página que no merece más de una crux desperationis; para más inri, los problemas editoriales y hermenéuticos se superponen, lo que muchas veces fuerza la emendatio ope codicum y aun la emendatio ope ingenii. Las dificultades muestran mayor densidad en determinados episodios y secciones; sin embargo, incluso tras aquello que inicialmente parece diáfano se descubre un rico y complejo universo de referencia, de orden literario y linguístico. Paradigma de ello es el capítulo «De la pelea que ovo 
don Carnal con la Quaresma», donde el Arcipreste parodia un género para el que sólo contamos con ejemplos posteriores, casi todos cuatrocentistas: la carta de batalla (estrofas 1.071-1.072)1; ahí también, se perfila nítida la burla a que somete el estilo épico, ya sea en la estrofa 1.089 o en la $1.106^{2}$.

Los ecos de la cuaderna vía previa son múltiples y a menudo escapan al ojo del medievalista más avezado, como ocurre en dos casos concretos. En el primero de ellos, nos pone sobre aviso la curiosa rima conejos-vallejos (estrofa 1.117), tras la que veo otro eco más (y hay muchos, desde la estrofa 14 en adelante) del Libro de Alexandre ${ }^{3}$. El inicio de la estrofa 475 de la obra no deja lugar a duda ${ }^{4}$ :

Yazíeles entre medio un fermoso vallejo, rico de mucha liebre e de mucho conejo.

(Libro de Alexandre)

Allí lidian las ostias con todos los conejos

[...]

de escamas e de sangre van llenos los vallejos.

(Libro de Buen Amor)

Mucho más reveladora es la coincidencia, igualmente inadvertida por la crítica, en nada menos que tres de las cuatro rimas de la estrofa 1.091 del Arcipreste y la 87 del Martirio de san Lorenzo de Gonzalo de Berceo, señal más que probable de que el de Hita está bebiendo en el riojano, a pesar de la pobre tradición textual de esa pasión. A este respecto, poco importa el hecho de que ambas obras respondan a estímulos creadores diferentes o que el tono de ambos pasajes sea distinto por completo ${ }^{5}$ :

\footnotetext{
${ }^{1}$ Como se comprueba en las muchas páginas que Martín de Riquer ha dedicado al asunto, aunque ahora me interesan en particular el orto y expansión del género en Castilla, al que atiende Antonio Orejudo, ed., Cartas de batalla, Barcelona, PPU, 1993.

2 Aunque se le escapan algunos ejemplos claros, la atención de María Esperanza Sánchez Vázquez se dirige fundamentalmente hacia este episodio en «Fórmulas épicas en el Libro de Buen Amor», Francisco Toro Ceballos y Bienvenido Morros Mestres, coords., Juan Ruiz, Arcipreste de Hita, y el «Libro de buen amor». Congreso Internacional del Centro para la Edición de los Clásicos Españoles, patrocinado por el área del cultura del Ayuntamiento de Alcalá La Real... del 9 al 11 de mayo de 2002, Alcalá la Real, Ayuntamiento de Alcalá la Real, 2004, págs. 141-148.

3 Cito por la edición de Juan Casas Rigall, Libro de Alexandre, Madrid, Castalia, 2007, pág. 253.

${ }^{4}$ Esta precisa correspondencia no la recoge el ojo certero de Jorge García, «La influencia del Libro de Alexandre en el Libro de Buen Amor», Juan Ruiz, Arcipreste..., Toro Ceballos y Morros Mestres, coords., op. cit., págs. 183-198.

${ }^{5}$ Por otra parte, ello quita la pizca de razón que pudiera quedarles a cuantos editores ven en espinaça un sinónimo de espina, como G. B. Gybbon-Monypenny, cuya edición (Juan Ruiz, Libro del Buen Amor, G. B. Gybbon-Monypenny, ed., Madrid, Castalia, 1990) utilizo en las citas.
} 
Díssoli sant Laurencio: «Todas tus amenazas más sabrosas me saben que unas espinazas. Todos los tus privados y tú que me profazas non me fechés más miedo que palomas torcazas».

(Martirio de san Lorenzo)

Vino el cabrón montés con corços e torcazas, deziendo sus bramuras e muchas amenazas. «Señor», diz, «a la dueña, si conmigo la enlazas, non te podrá enpescer con todas sus espinaças».

(Libro de buen amor)

No bajaré al detalle, dada la brevedad de la presente nota; sin embargo, no puedo sino mostrar mi asombro ante la elevada concentración de despistes lexicográficos en este episodio del Libro. De los que he ido agavillando en lecturas sucesivas, tal vez los más llamativos sean los correspondientes a la ictiología, como utra (113a), hápax solo en apariencia, o tollo (1.115a). Contra estas dos voces se han estrellado casi todos los editores; de hecho, si la primera para algunos, guiados por Joan Corominas, es una clara alusión a la nutria ${ }^{6}$, de la segunda suele decirse que es sinónimo de la lija (especie citada, por cierto, con este preciso nombre en 1.109a) o pintarroja ${ }^{7}$. Aquélla, no obstante, apenas si encubre una referencia clara a la urta o hurta, denominación meridional para el Pagrus auriga (¿quién que haya estado un tiempo en la Bahía de Cádiz no ha comido urta a la roteña?), mientras ésta, escrita ora como tollo ora como toyo, es un sinónimo de cazón en diversos puntos del litoral español, particularmente en el Archipiélago Canario; no obstante, en Hispanoamérica sirve para identificar varias especies de tiburón, si es que no se usa como genérico para aludir a cualquier escualo ${ }^{8}$.

Aquí, acierta Joan Corominas (Juan Ruiz, Libro del Buen Amor, Joan Corominas, ed., Madrid, Gredos, 1967) y quienes a lo sumo ven un retruécano espina-espinaca, como agudamente señala Jacques Joset (Juan Ruiz, Libro del Buen Amor, Jacques Joset, ed., Madrid, Taurus, 1990, pág. 470). Lo mismo dice Alberto Blecua (Juan Ruiz, Libro del Buen Amor, Alberto Blecua, ed., Madrid, Cátedra, 1992, pág. 271).

${ }^{6}$ Tanto en su edición como en el Diccionario crítico etimológico castellano e hispánico (con José Antonio Pascual, [1981]). Y no deja de sorprender la interpretación que da al término, pues los mamíferos no encajan en el pasaje. Sobre él parece haber pesado la forma indoeuropea de la que proceden el inglés otter, el alemán Otter y el sueco utter.

${ }^{7} \mathrm{Y}$ no andan errados los tiros al comprobar que, en Levante, lija es el término con que comúnmente se conoce el marrajo.

${ }^{8}$ Mis notas al respecto son, digámoslo así, propias, en tanto en cuanto forman parte de mi competencia lingüística como simple aficionado a la ictiología. En su momento, entre otras muchas fuentes, manejé la tesis doctoral inédita de María Pilar Palanco, a la que tan solo tengo acceso indirecto gracias a los muchos materiales que vertió en la Enciclopedia Universal Multimedia Micronet, de la que fui Asesor Científico desde sus orígenes hasta 2001. 
El problema que me dispongo a abordar con más detalle supone un cambio radical en la identificación de una especie animal aludida, aunque no fuerza retoque alguno en la lección comúnmente aceptada. Leamos la estrofa 1.107:

\section{De parte de Bayona venién muchos caçones, mataron las perdizes, castraron los capones. Del rrío de Henares venián los camarones: fasta en Guadalquivir ponián sus tendejones.}

En mi opinión, con respecto a camarones ni un solo editor ofrece una solución satisfactoria, al menos no con la precisión y seguridad debidas: unos porque nada dicen al respecto; los demás porque cierran filas y coinciden en identificarlo con el cangrejo de río. Tan sólo Anthony N. Zahareas y Oscar Pereira atinan, en mi parecer, pero sin dar una sola prueba de saber de lo que hablan: «es decir, son camarones de río, de agua dulce y no de mar (cfr. núms. 1.1021.109)» ${ }^{9}$; del mismo modo, mi amigo Pablo Jauralde acierta al recordar ${ }^{10}$, lacónico, que camarón es sinónimo de quisquilla, aunque a uno le habría encantado que hubiese ahondado en la materia, considerada la diversidad de pareceres de cuantos le precedían.

De algún modo, el admirado maestro José Fradejas ${ }^{11}$ ha abanderado a cuantos defienden la equivalencia de camarón y cangrejo, una propuesta que, de entrada, choca con el propio étimo, pues del latín cammarus deriva, aunque de forma tortuosa, el español gamba ${ }^{12}$. Fradejas apela al testimonio de Andrés Laguna $^{13}$, y tiene razón en buena medida, pues aunque el segoviano persigue acabar con la confusión que, por aquel entonces, se daba entre cangrejo y camarón («Están en grandíssimo error los que por el cangrejo de Galeno y Dioscórides entienden aquella especie de camarón que en griego se llama gammaro y astaco, y por toda Italia se llama gambaro»), consigue precisamente lo contrario; de hecho, tras leerlo, no se sabe a ciencia cierta si está hablando del camarón o quisquilla o, simplemente, del cangrejo de río.

Sembrada la duda, tampoco sirven las entradas de los vocabularios antiguos, pues ni Alonso de Palencia, ni Antonio de Nebrija, ni Sebastián de Covarrubias resultan más precisos que Laguna. Se impone indagar en otros lugares; en ese sentido, el CORDE (Corpus Diacrónico del Español) y el DITEMA (Diccionario Español de Términos Médicos Antiguos) coinciden en una sola ficha, con la

\footnotetext{
${ }^{9}$ En Anthony N. Zahareas y Oscar Pereira, Itinerario del Libro del Arcipreste: Glosas críticas al «Libro de buen amor», Madison, The Hispanic Seminary of Medieval Studies, 1990, pág. 309.

${ }^{10}$ En su edición, prologada junto a Florencio Sevilla y anotada por él mismo (Barcelona: PPU, 1988), pág. 348.

11 José Fradejas, Geografía literaria de la provincia de Madrid, Madrid, CSIC-Instituto de Estudios Madrileños, 1958

12 Corominas-Pascual, Diccionario crítico etimológico, op. cit., bajo la voz «camarón».

13 Andrés Laguna, Amberes, Juan Latio, 1555, pág. 129.
} 
que yo contaba de antemano: la del códice escurialense que romancea el Tratado de las fiebres de Ischaq Israeli (fl. 890 a quo), que recomienda comer «cangrejos e camarones de río cochos con cevada» ${ }^{14}$. Al respecto, alguien podría sostener que camarón vale aquí lo mismo que cangrejo, pues no son raras las glosas explicativas a manera de binomio, procedimiento que, en opinión de Francisco Bernis, aclara la referencia del Arcipreste de Hita a otra especie animal. En esta ocasión, se trata de una volátil ${ }^{15}$ : «Juan Ruiz (s. XIV), en su Libro de Buen Amor, cita una vez «papagayo e orior», dos vernáculos que acaso se refieren al mismo pájaro». A pesar de que Bernis es, sin ningún género de duda, la máxima autoridad en la materia, creo que en esta ocasión se equivoca.

En mi opinión, el contexto no apoya su propuesta por varios motivos. Me llama la atención, por ejemplo, que el Arcipreste afirme categóricamente (1.615ab): «Son aves pequeñuelas papagayo e orior // pero qualquier dellas es dulce gritador». Con independencia del sentido que les demos a ambas fichas ornitológicas, el genial poeta parece no estar familiarizado (y no me extraña) con la vigorosa y arisca oropéndola, que no destaca precisamente por su pequeño tamaño: mide más o menos lo mismo que un mirlo, pero es tan robusta que lucha incluso con las rapaces pequeñas y medianas; es más, llegado el caso, se enfrentará incluso al búteo o ratonero. Por otra parte, al evitar el contacto con el hombre, esta especie no cuenta entre las aves canoras, por mucho que sus potentes agudos (que acaso Juan Ruiz sabía distinguir, a la manera de un experto ornitólogo) recuerden de nuevo al mirlo.

Con todo, estoy dispuesto a conceder que el Arcipreste acierta en ambos casos, pues el tamaño es, por principio, algo relativo, ya que depende del segundo miembro de la comparación (¿pequeño respecto de qué?); por añadidura, el silbo de la oropéndola se oye a larga distancia y se impone al canto de las demás aves, algo llamativo en un animal que no sobrepasa los veinticinco centímetros, aunque su envergadura alcanza casi los cincuenta. El plural, no obstante, quita enteramente la razón a Bernis y avisa al lector de que no se halla ante una glosa geminada sino que se está aludiendo a dos aves distintas. A este respecto, la identificación del orior u oriol con la oropéndola no admite duda, aunque es así gracias al latín oriolus, al catalán (oriol) y al gallego (ouriolo), pues en castellano el término aportado por el Libro de Buen Amor es un hápax ${ }^{16}$.

\footnotetext{
${ }^{14}$ En la edición de mi añorada amiga Ruth Richards (Madison: Hispanic Seminary of Medieval Studies, 1995), fol. 38r.

15 Francisco Bernis, Diccionario de nombres vernáculos de aves, Madrid, Gredos, 1995, pág. 131. A este estudioso se le escapan dos fichas fundamentales: el «falcón oriol» del Calila e Dimna y el «rey oriol» del Elena y María. La primera tiene el interés de coincidir con la imagen que del oriol dan los antiguos escudos y pendones de Orihuela, donde es un ave de presa.

${ }^{16}$ Como era de esperar, la forma tampoco aparece en la recogida de voces ornitológicas que llevó a cabo Keith Whinnom, A Glossary of Spanish Bird-Names, London, Tamesis Books, 1966. Aquí sólo se documenta «oropéndola».
} 
Atendamos, pues, al primer miembro del binomio y hablemos del papagayo. Antes de nada, recordemos que el loro y otros psitácidos no sólo proceden de América sino de Asia y África y que eran conocidos en Europa desde la Antigüedad, como vemos en Plinio el Viejo y otros autores (entre ellos, los enciclopedistas medievales, como Brunetto Latini en su Trésor). Algunos ejemplares especialmente parlanchines habían sido traídos de la remota India y desde la selva africana, donde habita el loro gris o yaco, especie capacitada sobre todas las demás para aprender a hablar o, más bien, repetir patrones sonoros de enorme variedad y riqueza. Ello explica que el Sendebar (ca. 1253) incluya ya el «Exemplo del omne e de la muger, e del papagayo e de su moça». Sobre la procedencia de esta ave dice Alfonso de Palencia (Universal vocabulario en latín y en romance [1490]): «Psitacus: 'papagayo'. Fállase en abundancia en las riberas de India e de Guinea. Tiene grand lengua, et por esso declara palabras pronunciadas saludando los ombres, e más a derechas pronuncia unas palabras que otras».

Añadamos que el papagayo está presente en toda la tradición trovadoresca: en los trovadores occitanos, que cuentan nada menos que con Las novas del papagay de Arnaut de Carcasses; en los cancioneiros gallego-portugueses, con la pastorela del rey don Denis, que se refiere a «Hu papagay muy fremoso», cuyo gracejo radica en su habilidad para hablar y cantar; o bien en los cancioneros castellanos, con citas de Juan Alfonso de Baena, el Marqués de Santillana y un poeta valenciano del Cancionero General, que nos deleita con un «Bell papagay ab penes d'esperança». Si nos preguntamos cómo han resuelto tal referencia los estudiosos de cada una de estas tradiciones hermanadas, cabe decir que de la manera más sencilla y lógica: todos, sin excepción, ven en el papagayo un lorito hablador, el ave gárrula por excelencia. Realmente, el valor que el Medievo da al término no difiere del actual, fuera de un caso sorprendente: el de un Enrique de Villena que ofrece un temprano eco de Catulo y que, al traducir el paser o gorrión de Lesbia, busca correspondencia nada menos que en papagayo $^{17}$.

Volvamos al crustáceo citado por Juan Ruiz y despejemos dudas apelando a la moderna zoología, pues en sus libros hallaremos la solución tras la que andamos. Gracias a ella, nos enteramos de que el camarón del Henares existe de hecho y que pertenece a la familia de los palaemonetes. La especie española es, en concreto, el Palaemonetes zariquieyi, conocido también como 'camarón ibérico', 'camarón de agua dulce', 'camarón de acequia' o 'gambita de acequia'. Aunque su hábitat principal está en las desembocaduras de los ríos, tampoco falta en sus cursos altos, incluso a gran distancia de la costa. En el inte-

17 En glosa al Tratado de la consolación, ed. Pedro M. Cátedra, Madrid, Turner, 1994, pág. 282. 
rior, fue muy abundante en la provincia de Madrid y, de acuerdo con la fama que refleja el Libro de Buen Amor y repiten otras fuentes, en el río Henares ${ }^{18}$, donde hace años se consideraba especie endémica y se cogía a cubos. En este río, tan familiar al Arcipreste, el camarón ibérico es muy escaso, dado que sólo prospera en aguas oxigenadas. Otra especie próxima a la citada, y presente en numerosos ríos peninsulares, es el Atyaephyra desmaresti ${ }^{19}$.

Aun cabe hacerse una última pregunta para que todo encaje. De su respuesta dependerá que imaginemos o no a este crustáceo concreto encuadrado en las filas de doña Cuaresma: ¿es comestible el camarón de acequia o gamba de agua dulce? En paralelo, hay que preguntarse si su consumo ha sido algo excepcional. Al respecto, los datos son concluyentes: siempre fue abundante y, en consonancia, en determinadas zonas su pesca e ingesta fueron algo habitual. Me basta el testimonio de Vicenç M. Rosselló i $\operatorname{Verger}^{20}$ : «El Palaemonetes, vulgarment anomenat gamba, era pescat abans de 1965 amb gran assiduïtat: hom arribava a una tona diària, i la seua destinació era tant la venda com a comestible, com la d'esca per als pescadors». Para alimento o como cebo de pesca, no es de extrañar el destino de la otrora abundante gambita de acequia, pues no se trata de una especie microscópica: téngase en cuenta que sus hembras alcanzan un tamaño nada despreciable, que ronda los cinco centímetros.

El Henares ha salido a relucir mucho antes en una de las continuas muestras del ingenio de Juan Ruiz (170b): «sembré avena loca, ribera del Henares ${ }^{21}$. Probablemente, se trata de una paremia, ya que la idea que sustenta tiene correspondencia en no pocos refranes, como lo es el que remata la cuarteta monorrima (un «antiguo retraer», como lo llama el Arcipreste), en mi opinión perfectamente antitética ${ }^{22}$ : «Quien en el arenal siembra non trilla pegu-

18 Así se expresan las Relaciones topográficas de los pueblos de España: Madrid (ed. Carmelo Viñas y Ramón Paz, Madrid, CSIC, 1949, pág. 621): «A los veinte y un capitulos dixeron que esta villa no tiene huertas regadios, porque han poco de ribera que alcanza entre el rio de Henares, tan poco que no es más de abrevaderos para ganados, y entre esos tiene plantados salces y pobos blancos, y no tiene frutales en ella sino las salcedas dichas y los pescados, que caen a la parte del río que tiene esta dicha villa de sus abrevaderos dichos. Tienen peces bogas, cachos y machos y camarones y anguilas, que se pescan los vecinos». Siento que el pasaje no sirva para deslindar camarones de cangrejos y que, para muchos, constituya una razón adicional para ver una alusión a este último crustáceo.

19 Aunque el Henares no aparece en la relación que hacen J. Oscoz y C. Durán, «Contribución al conocimiento del camarón de río, Atyaephyra desmaresti (Millet, 1831) (Decapoda, Natantia), en la cuenca del Ebro (España)», Zool. Baetica, 16, 2005, págs. 155-159, ello no indica que no se dé en nuestra zona de interés.

${ }^{20}$ L'Albufera de València (Barcelona, Publicacions de l'Abadia de Montserrat, 1995), pág. 70 (en el apartado «3.2.2. Els crustacis de l'Albufera»).

${ }^{21}$ Más profundo, y con tino total, cala Francisco Rico en «Senbré avena loca ribera del Henares», Primera cuarentena, Barcelona, Quaderns Crema, 1982, págs. 53-55.

${ }^{22}$ No puedo coincidir con quienes han visto en la ribera una alusión al mismo arenal del último verso. Para que la construcción sea perfecta, basta con que uno de los dos miembros, no 
jares $»^{23}$. En cualquier caso, el significado resulta diáfano: 'perdí el tiempo en una empresa vana', 'hice un esfuerzo baldío'; de hecho, año tras año, allá por primavera, llevo algunas espigas de Avena fatua o Avena sterilis (¡cuán elocuente es su nombre científico!) a mis estudiantes ${ }^{24}$, justo cuando estamos leyendo el Libro de Buen Amor, para que vean que no porta grano alguno. Así, utilizar los limos de un río, el suelo fértil por excelencia, para cultivar esta gramínea es lo mismo que 'lavar la cabeza a un tiñoso', 'echar agua a la mar' e incluso 'hacer un pan con unas hostias'. Por tanto, nada hay, en principio, de específicamente sexual en esta expresión, frente a lo que quieren algunos estudiosos, que tienen su alférez o abanderado en G. B. Gybbon-Moneypenny ${ }^{25}$. Por supuesto, a nadie se le escapa la connotación erótica que, casi automáticamente, comporta el verbo sembrar, potenciada aquí por el contexto amoroso en que se embute. Ahora bien, queda claro que, en origen, la expresión tenía un sentido ajeno por completo a esta deriva ${ }^{26}$.

ambos, carezca de sentido: lo es sembrar una planta de fruto vano en una buena tierra, como lo es también esperar cosecha de un arenal.

${ }^{23}$ Huelga señalar que este refrán tiene resonancias bíblicas, pues nos remite a la Parábola del Sembrador.

${ }^{24}$ Sobre la planta y su nombre, véase Pilar García Mouton, «Aragonés ballueca, 'avena loca'», Archivo de Filología Aragonesa, 34-35, 1984, págs. 301-313.

${ }^{25}$ Dice en la nota correspondiente (pág. 143): «María Rosa Lida nota (RFH, II, 1940, página 116) que la avena es símbolo de la lujuria. En inglés, sigue siendo proverbial 'to sow one's wild oats', en el sentido de divertirse con amoríos cuando mozo».

${ }^{26}$ Mi siempre brillante amigo Luis Fernández Gallardo me recuerda que, para Luis Beltrán, Razones de buen amor (Madrid: Fundación Juan March, 1977), pág. 114, podría comportar un sentido sexual específico, pues recuerda la referencia bíblica a Onán, del que se dice «semen fundebat in terram» (Gen 38, 9). 